\title{
STABILITY OF AN INCOMPLETE GAMMA-TYPE FUNCTIONAL EQUATION
}

\author{
Young Whan LeE AND Byung Mun CHOI
}

Abstract. We investigate the Hyers-Ulam-Rassias stability of an incomplete gamma-type functional equation

$$
\begin{aligned}
& f\left(\phi_{1}\left(x_{1}\right), \cdots, \phi_{n}\left(x_{n}\right), \psi_{1}\left(y_{1}\right), \cdots, \psi_{m}\left(y_{m}\right)\right) \\
& \quad=\theta\left(x_{1}, \cdots, x_{n}, y_{1}, \cdots, y_{m}\right) f\left(x_{1}, \cdots, x_{n}, y_{1}, \cdots, y_{m}\right) \quad+\lambda\left(x_{1}, \cdots, x_{n}, y_{1}, \cdots, y_{m}\right)
\end{aligned}
$$

with a restricted domain. By this result we obtain the stability of the incomplete gamma functional equation

$$
f(x+1, y)=x f(x, y)+e^{-y}(y)^{x}
$$

with a restricted domain.

Mathematics subject classification (2000): 39B22, 39B72.

Key words and phrases: Functional equation, stability of functional equation, Hyers-Ulam-Rassias stability, incomplete gamma function.

\section{REFERENCES}

[1] J. Baker, J. Lawrence And F. Zorzitto, The stability of the equation $f(x+y)=f(x)+f(y)$, Proc. Amer. Math. Soc. 74 (1979), 242-246.

[2] C. Borelli, On Hyers-Ulam stability for a class of functional equations, Aequationes Math. 54, 74-86.

[3] G. L. FORTI, Hyers-Ulam stability of functional equations in several variables, Aequationes Math. 50, $146-190$.

[4] R. GER, Superstability is not natural, Rocznik Naukowo-Dydaktyczny WSP Krakkowie Prace Mat. 159 (1993), 109-123.

[5] D.H. Hyers, On the stability of the linear functional equation, Proc. Nat. Acad. Sci. U. S. A. 27 (1941), 222-224.

[6] D. H. Hyers, Th.M. RASSIAS, Approximate homomorphisms, Aequatioues Math. 44 (1992), 125-153.

[7] D. H. Hyers, G. IsAC AND TH. M. RASSIAS, Stability of functional equations in several variables, Birkhäuser-Basel-Berlin, 1998.

[8] K. W. Jun, G. H. Kim AND Y.W. LeE, Stability of generalized gamma and beta functional equations, Aequation Math. 60 (2000), 15-24.

[9] S.-M. JUNG, On the general Hyers-Ulam stability of gamma functional equation Bull, Korean Math. Soc. 34 No 3 (1997), 437-446.

[10] S.-M. JuNG, On the stability of the gamma functional equation, Results Math. 33 (1998), 306-309.

[11] G. H. KIM, Y. W. LEE, The stability of the beta functional equation, Babes-Bolyai Mathematica XLV 1 (2000), 89-96.

[12] Y. W. LEE, On the stability of a quadratic Jensen type functional equation, J. Math. Anal. Appl. 270 (2002), 590-601.

[13] Y. W. LEE, The stability of derivations on Banach algebras Bull, Institute of Math. Academia Sinica 28 (2000), 113-116. 
[14] P. Natalini, B. Palumbo, Inequalities for the incomplete gamma function, Math. Inequal. Appl. 3 no. 3 (2000), 69-77.

[15] TH. M. RASSIAS, On the stability of the linear mapping in Banach spaces, Proc. Amer. Math. Soc. 72 (1978), 297-300..

[16] TH. M. RASSIAS, On a problem of S. M Ulam and the asymptotic stability of the Cauchy functional equation with applications, General Inequalities 7 MFO Oberwolfach Birkhäuser Verlag Basel ISNM 123 (1997), 297-309.

[17] TH. M. RASSIAS, On the stability of the quadratic functional equation and its applications, Studia Univ. Babes-Bolyai XLIII 3 (1998), 89-124.

[18] TH. M. RASSIAS, The problem of S.M. Ulam for approximately multiplicative mappings, J. Math. Anal. Appl. 246 (2000), 352-378.

[19.] TH. M. RASSIAS, On the stability of functional equations in Banach spaces, J. Math. Anal. Appl. 251 (2000), 264-284.

[20] TH. M. RASSIAS, On the stability of functional equations and a problem of Ulam, Acta Applications. Math. 62 (2000), 23-130.

[21] TH. M. RASSIAS, P. SEMRL, On the behavior of mapping that do not satisfy Hyers-Ulam stability, Proc. Amer. Math. Soc. 114 (1992), 989-993.

[22] T. TRIF, On the stability of a gamma-type functional equation, to appear.

[23] S. M. Ulam, Problems in Modern Mathematics Chap. VI, Science editions, Wiley, New York, 1960. 